\title{
Evaluation of dental staining using a dentifrice containing chlorhexidine and zinc acetate. A doble blind randomized clinical trial
}

Avaliação de dentifrício contendo clorexidina e acetato de zinco. Estudo clínico controlado randomizado duplo cego

Emanuel da Silva ROVAI ${ }^{1}$, Tábata de Mello TERA ${ }^{1}$, Andrea Carvalho DE MARCO ${ }^{1}$, Maria Aparecida Neves JARDINI ${ }^{1}$, Mauro Pedrine SANTAMARIA ${ }^{1}$, Warley David KERBAUY ${ }^{1}$

1 -Institute of Science and Technology - UNESP - Univ Estadual Paulista - School of Dentistry - São José dos Campos - SP - Brazil

\section{ABSTRACT}

Objective: The aim of this study was to evaluate whether the association of chlorhexidine with zinc acetate in dentifrices formulations could reduce the emergence of extrinsic tooth stain. As second outcome check the clinical gingival parameters. Methods: 30 volunteers were randomly divided into three groups: $\mathrm{CHX}+\mathrm{Z}$, consisting of 10 participants who used a dentifrice with $0.8 \%$ chlorhexidine gluconate and zinc acetate $1.16 \%$; CHX group, with 10 participants who used a similar formulation dentifrice without zinc acetate, and the Placebo group also with 10 participants who used a dentifrice formulation similar but without the chlorhexidine and zinc acetate. Patients were assessed at baseline and 60 days when the indexes of plaque, gingival bleeding and staining were collected. Results: The results showed that by day 60 , there was a decrease of both plaque index(PI) and the gingival index(GI) for all groups. Additionally, it was observed that both groups using dentifrice containing chlorhexidine, showed more stain than placebo. The $\mathrm{CHX}+\mathrm{Z}$ group showed less stain compared to the CHX group, but the difference was not statistically significant. The difference between Placebo and Chlorhexidine Groups was statistically significant $(p<0.05)$ when considered the stain intensity and area plus intensity scores. The $\mathrm{CHX}+\mathrm{Z}$ group was as efficient in $\mathrm{PI}$ and GI reduction as the CHX group. Conclusions: The association of chlorhexidine with zinc acetate showed no additional benefits regarding reducing the staining. The dentifrices containing chlorhexidine presented higher reduction of GI and PI when compared to Placebo group.

\section{KEYWORDS}

Chlorhexidine; Zinc acetate; Staining index; Plaque index; Gingival index.

\section{RESUMO}

Objetivo: O objetivo deste estudo foi avaliar se a associação de clorexidina com acetato de zinco em dentifrícios poderia reduzir o aparecimento de manchas dentárias extrínsecas. Como segundo objetivo verificar os parâmetros clínicos gengivais. Materiais e métodos: 30 voluntários foram divididos aleatoriamente em três grupos: $\mathrm{CHX}+\mathrm{Z}$, composta por 10 participantes que usaram um creme dental com $0,8 \%$ de gluconato de clorexidina e acetato de zinco 1,16\%; grupo CHX, com 10 participantes que usaram uma formulação de dentifrício semelhante, porém sem acetato de zinco, e o grupo do placebo também com 10 participantes que usaram uma formulação dentífrica semelhante, mas sem a clorexidina e sem acetato de zinco. Os pacientes foram avaliados no início do estudo e após 60 dias, quando foram coletados os índices de placa, sangramento gengival e manchas. Resultados: Os resultados revelaram que ao dia 60 , havia uma redução em ambos os índices, de placa (IP) e do índice gengival (IG) em todos os grupos. Além disso, observou-se que em ambos os grupos que utilizou dentifrício contendo clorexidina, mostrou um maior índice de manchas maior do que o placebo. O grupo $\mathrm{CHX}+\mathrm{Z}$ apresentou um índice de manchas menor em relação ao grupo CHX, mas a diferença não foi estatisticamente significativa. A diferença entre os grupos quem continham clorexidina e placebo foi estatisticamente significativa $(\mathrm{p}<0,05)$ quando considerado a intensidade e a área de manchas + intensidade das manchas. O grupo CHX + $\mathrm{Z}$ foi tão eficiente na redução IP e IG quanto o grupo CHX. Conclusão: A associação de clorexidina com acetato de zinco não mostraram benefícios adicionais em relação a redução de manchas extrínsecas . Os dentifrícios com clorexidina apresentaram maior redução de IG e IP quando comparado ao grupo placebo.

\section{PALAVRAS-CHAVE}

Clorexidina; Acetato de zinco; Índice de manchas; Índice de placa; Índice gengival. 


\section{INTRODUCTION}

C hlorhexidine is a cationic biguanide with broad antimicrobial activity. It is the most effectively antiplaque and anti-gingivitis agent used in dentistry due to its duration and spectrum of action.[1,2] It causes damage to bacteria cytoplasmic membrane, leading to lysis of cell, being bacteriostatic or bactericidal. It has an affinity for a large variety of substrates and persists in toral surfaces, as a result of its high substantivity. [3]

Several formulations have been studied in different vehicles and concentrations, due to anti-plaque activity, prevention of periodontal and caries diseases. Although the literature shows several studies regarding clorhexidine effectiveness, it is known that prolonged utilization of this substance might cause side effects, such as altered taste, burning sensation, irritation of the mucosa, and development of dental stains. [4] Reports on appearance of extrinsic dental stains have been described. This pigmentation occurs due to precipitation of chlorhexidine products, which interact with pigments derived from food, on oral surfaces.[5]

It was reported that $0.12 \%$ chlorhexidine formulation might cause adverse effects to users light, as staining on teeth. McCoy et al. noticed staining of teeth, tongue, and restorations in $18 \%$ of patients using $0.12 \%$ chlorhexidine for 14 days. In 2006, Guimarães et al. showed that $55 \%$ of patients who used rinse of $0.12 \%$ chlorhexidine associated with $0.05 \%$ presented dental stains. At the end of last century new formulations containing zinc emerged with the objective to reduce dental staining. [4,6,7]

Zinc is used in attempt to minimize dental stains caused by chlorhexidine. [8,9] However, factors such concentration of chlorhexidine and period of use might be related to the appearance of stainings. Another factor that may favor the appearance of stains is the lack of dental plaque removal before the use of chlorhexidine.[10] Thus, the aim of the present study was to evaluate a dentifrice containing chlorhexidine digluconate and zinc acetate used for a period of 60 days, on the development of extrinsic tooth stains.

\section{MATERIALS AND METHODS}

This study was approved by the Ethics in Research Involving Human Subjects under protocol No. 022/2009-PH/CEP.

\section{Study design}

For this double-blind randomized clinical study, 30 volunteers of both genders aging 18-50 years were recruited among patients from São José dos Campos Dental College. All patients were informed about the purpose and procedures of the research to be performed, and signed a consent form.

\section{Population}

Inclusion Criteria

a) Good general and oral health

b) Have at least twenty-four teeth in mouth

c) Do not smoke,

d) Do not wear braces

e) Do not use any type of mouthwash

f) Do not use antibiotics 6 months prior to the study.

\section{Randomization and allocation}

The volunteers were allocated to groups (Figure 1), according to a computergenerated list. This process was accomplished by employing different people for treatment and exams. The randomization code was not broken until all data had been collected. The treatment groups were not revealed to the clinical examiner and professional statistician. 


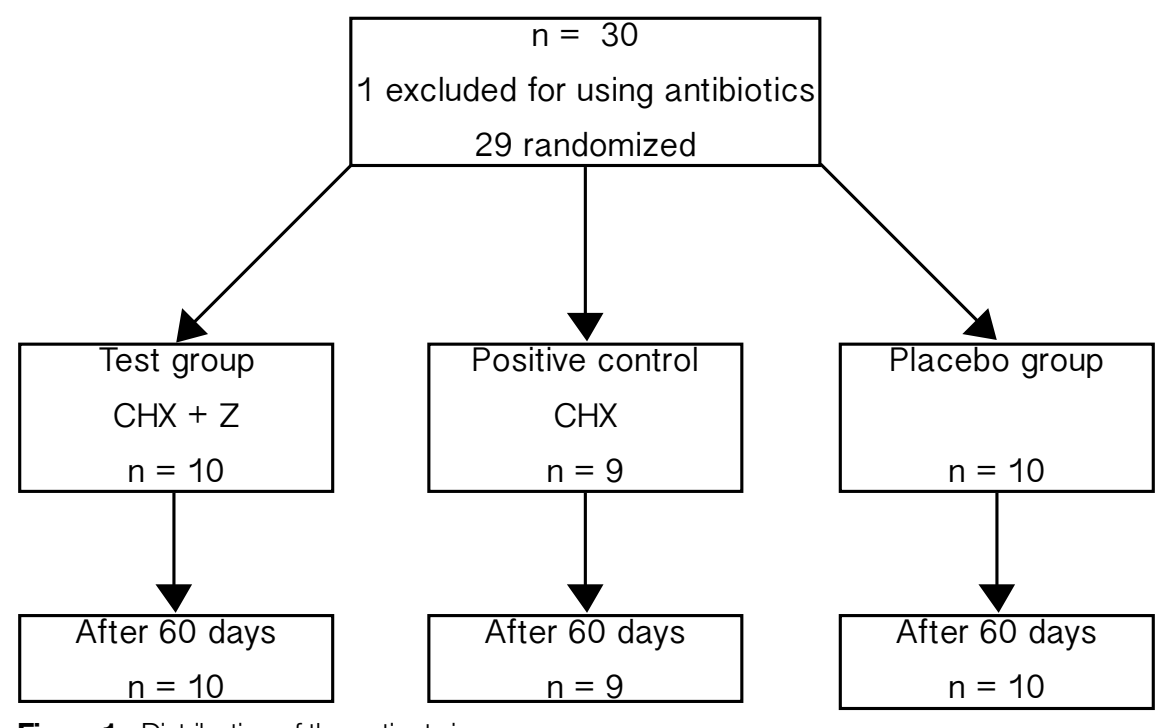

Figure 1- Distribution of the patients in groups.

\section{Treatment}

Before the beginning of the study, all participants received oral hygiene instruction with atraumatic brushing technique and using dental floss, in order to standardize the way participants would make mechanical cleaning of the teeth. They received standardized toothbrushes and dental floss (Sorriso - Kolynos, Br). They were also instructed to put the same amount of toothpaste to perform brushing, which should be carried out for two minutes, three times per day for sixty days. All patients were asked about their consumption of foods and substances that might stain teeth, especially regarding the use of coffee, tea, red wine, and foods containing dyes.

Each participant was asked about the occurrence of any unusual reaction. At the end of the study, all stains that emerged were removed with professional cleaning.

The groups were as follows (Figure 1):

Group CHX+Z: 10 participants using a dentifrice with the following formulation: $2 \%$ Titanium Dioxide, $0.2 \%$ Aspartame, 0.04\% Saccharin, 8\% Glycerol, 12\% Sorbitol, $1 \%$ peppermint menthol essence, $0.6 \%$ chlorhexidine gluconate, $0.8 \%$ Zinc acetate, and $1.16 \%$ Natrosol gel.

Group CHX: 10 participants using a dentifrice produced by the same compounding pharmacy with similar formulation, except for the zinc acetate.

Group Placebo: 10 participants using a dentifrice produced by the same compounding pharmacy, but without chlorhexidine and zinc acetate.

\section{Treatment}

The following clinical parameters were evaluated:

Gingival Index (GI) according to Löe and Silness assessed at four sites: mesial-buccal, buccal, distal-buccal and lingual. All teeth were examined at baseline and 60 days, excluding third molars. [11]

The plaque index (PI) used was Turesky Index et al., a modification of the Quigley and Hein. Data were collected simultaneously to the gingival index assessments. [12,13]

Stains at buccal and lingual surfaces of incisors and canines were evaluated according to Macpherson et al. In the original article, canine teeth were not considered. The stain area, the intensity of staining and also the association of area and intensity of stains were considered for incisive tooth. Teeth were divided into three parts: body, approximal and gingival (Figure 2).[14] 


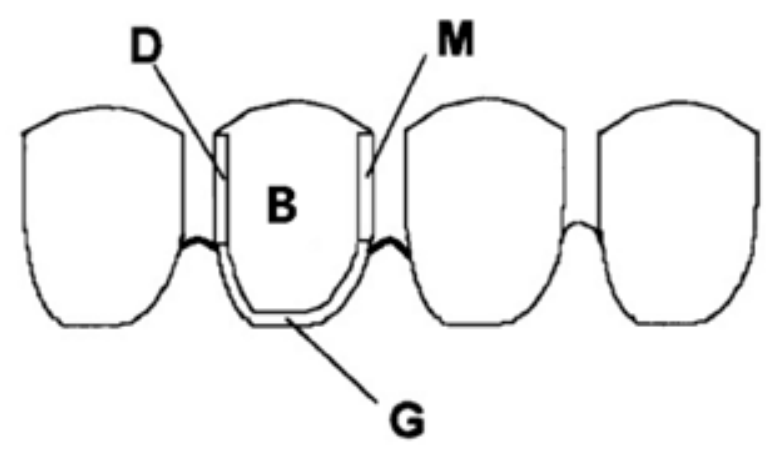

Figure 2 - Schematic drawing of the studied tooth areas. Figure adapted form MacPherson et al. (J Clin Periodontol 2000; 27:854859) showing stain sites: $\mathrm{B}$ - body; D - distal area; $\mathrm{M}$ - mesial area and $\mathrm{G}$ - gingival area.

Briefly, the method used by Macpherson et al. was: Stain evaluations were performed by one examiner and recorded by a writer. Stain accumulation on the index teeth was scored using a modification of the Lobene stain scoring index. This involved visual stain assessment of the buccal/labial and lingual/palatal aspects of the index teeth. The modification consisted of dividing each aspect into 4 separate sites (Fig. 1) instead of only 2 (gingival and body): gingival (G): $2 \mathrm{~mm}$ wide strip running parallel to the gingival margin. The limit towards the incisal edge was given by the end of the interdental papilla; body of tooth (B): central area of buccal/lingual aspect, between gingival and distal/mesial sites, extending to incisal edge; mesial (M): visible area between line angle and adjacent tooth, ending at the interdental papilla (i.e. start of gingival site); distal (D): as for mesial (M) site. Stain was recorded using 2 separate characteristics, namely intensity and area (extent) as suggested by Lobene. The criteria for these 2 parameters were also slightly modified to provide better discrimination at the lower end of the scale and to take into account anatomical differences between the different sites. $[14,15]$ The criteria and codes for intensity were:

$0=$ no stain present, natural tooth coloration

$1=$ faint stain

$2=$ clearly visible stain, orange to brown

$3=$ dark stain, deep brown to black
The area (extent) of the stain was recorded only if an intensity score of 2 or 3 was given. The area criteria and codes for approximal and gingival sites were:

$$
\begin{aligned}
& 1=\text { thin line, can be continuous } \\
& 2=\text { thick line or band } \\
& 3=\text { covering total area }
\end{aligned}
$$

The criteria and codes for area of the body of stained tooth are shown below.

At buccal/labial surfaces:

$1=$ Stain limited to pits/grooves.

$2=$ Stain outside pits/grooves, up to $10 \%$ of the area affected.

$3=$ Stain outside pits/grooves, more than $10 \%$ of the area affected.

In Lingual/palatal surfaces:

$1=\mathrm{Up}$ to $1 / 3$ of the area affected

$2=$ Between $1 / 3$ and $2 / 3$ of the area affected

$3=$ more than $2 / 3$ of the area affected

\section{Examiner Calibration:}

The following data were collected at baseline and 60 days by a single calibrated examiner who was blinded in relation to the toothpaste used by each participant, and data were self-recorded.

The calibration was made by repeating a third of the sample 24 hours after the first examination. The parameters considered were: gingival index and tooth stains. The results were analyzed by intra-examiner Kappa test.

\section{Statistical analysis:}

Mean and standard deviation values of each parameter were described. The data showed normal distribution by Shapiro-Wilk. Statistical analysis was performed by Analysis of Variance test and the Tukey test as a post-hoc test using computer software (SIGMA PLOT for Windows, version 12.0 - State College, Pennsylvania, USA. Minitab Inc.). 
To evaluate the differences within each group and among groups the level of significance was set at $5 \%$.

\section{RESULTS}

In relation to Gingival Index, only the groups CHX and $\mathrm{CHX}+\mathrm{Z}$ showed a statistically significant difference comparing baseline and 60 days, with $\mathrm{p}$ values $<0.001$, and the Placebo group with $\mathrm{p}=0.065$. When comparison between groups $\mathrm{CHX}+\mathrm{Z}$ and $\mathrm{CHX}$ was performed, the differences were not statistically significant. When compared the same groups with Placebo the difference was significant. (Figure 3).

Related to plaque index, mean values and standard deviation of groups at baseline Placebo, $\mathrm{CHX}+\mathrm{Z}$ and CHX were respectively $0.983 \pm$ $0.894,1.185 \pm 0.449$ and $1.264 \pm 1.089$, and the differences were not statistically significant. In the final evaluation period (60 days) no statistically significant differences were detected among them. There was a reduction of PI in all groups studied and when compared baseline and 60 days, all groups had statistically significant reduction with $\mathrm{p}<0.001$. The data are shown in Figure 4.
Stain index (SI) average values and standard deviations of the groups Placebo, $\mathrm{CHX}+\mathrm{Z}$ and $\mathrm{CHX}$ at baseline and final assessment period are shown in Figure 4.

As can be observed in Figure 5, the Placebo group was the only group that did not show significant stain variation between baseline and 60 days, comparing the area, intensity and area+intensity.

At baseline the groups Placebo, $\mathrm{CHX}+\mathrm{Z}$ and $\mathrm{CHX}$ showed average and standard deviation regarding the stained area of 0.1497 $\pm 0.1072,0.2891 \pm 0.2314$ and $0.1684 \pm$ 0.2083, respectively. Comparison among groups at baseline showed no statistically significant difference with $p>0.05$. After 60 days, all groups showed increase in levels of staining, with mean and standard deviation of $0.2435 \pm$ 0.2947, $0.6906 \pm 0.6505$ and $0.8576 \pm 0.4927$, respectively to Placebo, $\mathrm{CHX}+\mathrm{Z}$ and $\mathrm{CHX}$. For multiple comparison analysis, $\mathrm{CHX}$ versus Placebo group showed $p=0.004$; group Placebo versus $\mathrm{CHX}+\mathrm{Z}$ resulted in $\mathrm{p}=0.040$, and $\mathrm{CHX}+\mathrm{Z}$ versus CHX presented $\mathrm{p}=0.620$. Thus, $\mathrm{CHX}+\mathrm{Z}$ and CHX groups had statistically significant increase in the stained area as compared with the Placebo group, but the difference between the two was not statistically significant.
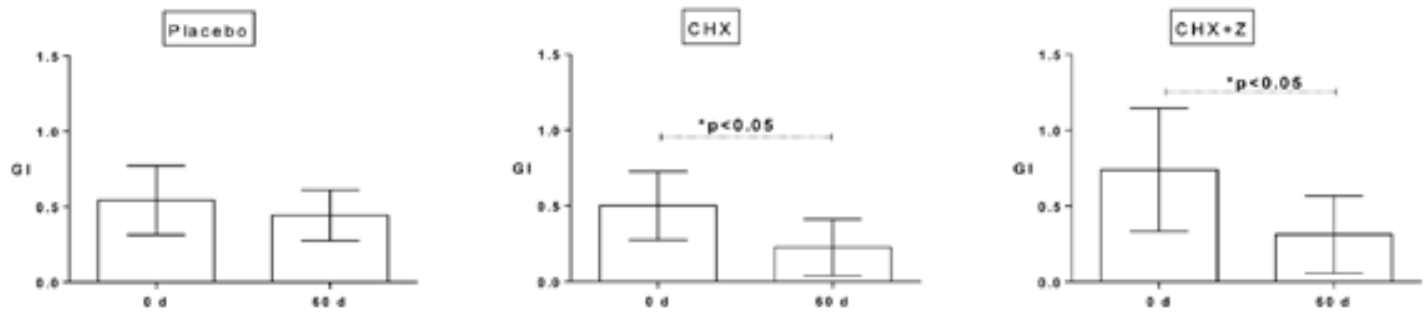

Figure 3 - Gingival Index at baseline and 60 days in Groups CHXÜZ, Placebo and CHX. Group CHXÜX and CHZ showed p $<0.001$ and the Placebo Group p $=0.065$
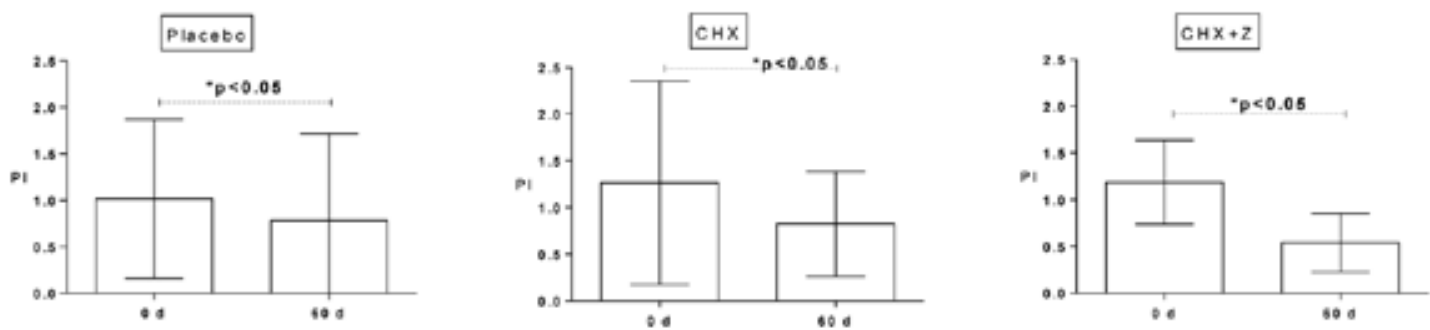

Figure 4 - Plaque Index at baseline and 60 days in Groups $\mathrm{CHXÜZ,} \mathrm{Placebo} \mathrm{and} \mathrm{CHX.} \mathrm{P-values} \mathrm{comparing} \mathrm{baseline} \mathrm{and} 60$ days in all groups $<0.001$ 

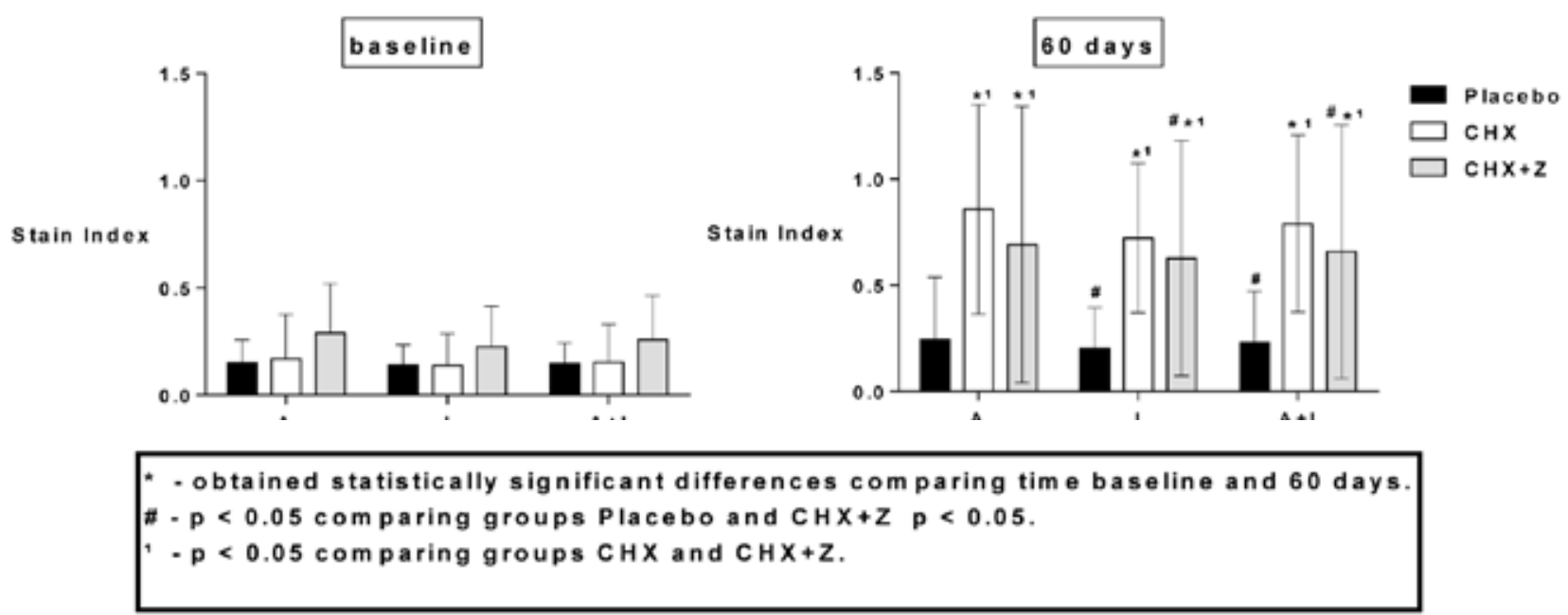

Figure 5 - Stain Index. Comparison of baseline and 60 days on the stained area (A), intensity stains $(I)$ and area + intensity stains $(A+I)$.

\section{DISCUSSION}

The use of dentifrices is an important tool against caries and periodontal disease. However, the association of mechanical action of brushing and flossing with the chemical control by chlorhexidine can be a great ally for plaque control. Nevertheless, studies have shown that the chronic use of chlorhexidine might cause side effects already described for McCoy et al., namely changes in dental surfaces such as stains, loss of taste, burning sensations or irritation of the mucosa, thus stimulating the search for new chemical compounds that may minimize the side effects and being affordable to the population. With this objective, we evaluated the effect of a dentifrice containing chlorhexidine associated with zinc acetate for a period of 2 months. [4]

During the period of the study we compared the results of the 3 groups: CLX $+\mathrm{Z}$ (test), CLX (positive control) and Placebo, and noted that group using dentifrice containing chlorhexidine associated with zinc acetate showed an improvement in periodontal clinical parameters and also showed a lower tendency to formation of extrinsic dental stains (intensity and area + intensity) compared to the positive control group, although this difference was not statistically significant.
The data showed that the PI had a statistically significant reduction in all groups when comparing baseline and 60 days, being slightly higher in the $\mathrm{CHX}+\mathrm{Z}$. This reduction occurred even in the placebo group due to the fact that all patients have been instructed about oral hygiene before the beginning of the study and also by monitoring every 15 days, leading to increased motivation for plaque control.

About $50 \%$ of the participants of this study were dental students with average of 23 years of age. This might explain the equivalence of gingival index, and stain index at baseline. Although we have not performed dental prophylaxis for the groups no interference on the results was detected, as there was no difference among groups at baseline.

In Sanz et al. study, the positive control received $0.12 \%$ chlorhexidine mouthwash while the test group used a dentifrice containing $0.4 \%$ chlorhexidine plus zinc. In the present study, the same concentration of dentifrices used in both groups prompted to an easier comparison, once the component zinc was the only variable in question.[7]

The ADS (Anti-Descoloration System) composed of ascorbic acid (vitamin C) and sodium metabisulfate has been associated with 
chlorhexidine in order to reduce the formation of stains. Solis et al observed a decrease of close to $50 \%$ in formation of dental stains when compared with to conventional mouthwash containing chlorhexidine. However, it is important to note that the assessed period of 15 days and $0.2 \%$ in concentration were one fourth of those used in our study. Another study used the aluminum lactate, but Rathe et al. found no statistically significant difference when compared extrinsic stains between the test and positive control.[16,17]

Different studies have tested the prolonged use of mouthwash with lower concentrations of chlorhexidine in order to reduce the side effects, but Hoffman et al. concluded that to maintain the gold standard for this substance its concentration must be kept at least at $0.1 \%$ in mouthwash form.[18]

Oltramari - Navarro et al. tested dentifrices containing $0.5 \%$ and $0.75 \%$ chlorhexidine for 3 months and found that $0.5 \%$ chlorhexidine being more suitable for use in orthodontic patients because no significant increase in stain index and improvement in clinical parameters were observed. Group receiving 0.75\% chlorhexidine showed a significant increase in stain indexes and also improvement in clinical parameters. In our study, we employed a similar concentration of chlorhexidine $(0.8 \%)$, but associated with zinc acetate and also did not find a reduction in the appearance of stains when compared with the group that used only chlorhexidine [19].

At the end of this study, two subjects, one from $\mathrm{CHX}+\mathrm{Z}$ group and other from CHX group showed SI index values significantly greater than the others. Knowing that the stains formation can vary according to the individual in the use of chlorhexidine these patients reported in their forms that had consumed foods with dyes in frequency and amount far above than the other participants, such as coffee, red wine and cola.[20]

Some limitations of our study should be considered. The first one is sample size. Although our study presented a similar sample size compared to other studies, additional studies with larger sample size are recommended. Another limitation is the method of evaluation of the stains. We used a method that is considered subjective, even being consolidated by Macpherson et al. There are more objective methods that can be used, such as spectrophotometry.[14,16] Despite these limitations, studies aiming to evaluate tooth stains caused by chlorhexidine have used the same methodology.

\section{CONCLUSION}

Within the limitations of the present study, it can be concluded that in both groups that used chlorhexidine, the stains index was higher than placebo. The association of chlorhexidine with zinc acetate showed no additional benefits regarding reducing the staining .The dentifrices containing chlorhexidine presented higher reduction of GI and PI when compared to Placebo group.

\section{REFERENCES}

1. Twetman, S. Antimicrobials in future caries control? A review with special reference to chlorhexidine treatment. Caries Res. 2004 May-Jun;38(3):223-9.

2. Elworthy A, Greenman J, Doherty FM, Newcombe RG, Addy M. The substantivity of a number of oral hygiene products determined by the duration of effects on salivary bacteria. J Clin Periodontol. 1996;67(6):572-6.

3. Herrera D, Roldán S, Santacruz I, Santos S, Masdevall M, Sanz M. Differences in antimicrobial activity of four commercial $0,12 \%$ chlorexidine muothrinse formulations: an in vitro contact test and salivary bacterial counts study. J Clin Periodontol. 2003 Apr;30(4):307-14.

4. McCoy LC, Wehler CJ, Rich SE, Garcia RI, Miller DR, Jones JA. Adverse events associated with chlorhexidine use: results from the Department of Veterans Affairs Dental Diabetes Study. J Am Dent Assoc. 2008 Feb;139(2):178-83.

5. Jones CG. Chlorhexidine: is it still the good standard? Periodontology 2000. 1997 oct;15:55-62.

6. Guimaraes AR, Peres MA, Vieira de S, Ferreira RM, Ramos-Jorge ML, Apolinario S. Self-perception of side effects by adolescents in a chlorhexidine-fluoride-based preventive oral health program. J Appl Oral Sci. 2006;14(4):291-6.

7. Sanz M, Vallcorba N, Fabregues S, Miller I, Herkstroter F. The effect of a dentifrice containing chlorhexidine and zinc on plaque, gingivitis, calculus and tooth staining. J Clin Periodontol. 1994 Jul;21(6):431-7.

8. Simons D, Brailsford S., Kidd EAM, Beighton D. The effect of chlorhexidine acetate/xylitol chewing gum on plaque and gingival indices of elderly occupants in residential homes. A 1-year clinical trial. J Clin Periodontol. 2001 Nov;28(11):1010-5. 
9. Giertsen E, Scheie A, Rolla G. Inhibition of plaque formation and plaque acidogenicity by zinc and chlorhexidine combinations. Scand Dental Res. 1988 ;96(6):541-550.

10. Zanatta FB, Antoniazzi RP, Rösing CK. Staining and calculus formation after $0.12 \%$ chlorhexidine rinses in plaque-free and plaque covered surfaces: a randomized trial. J Appl Oral Sci. 2010 Sep-0ct;18(5):515-21.

11. Löe H, Silness J. Periodontal disease in pregnancy. Acta Odontol Scand. 1963;21:533-51.

12. Turesky S, Gilmore ND, Glickman I. Reduce plaque formation by the chloromethyl analogue of vitamine C. J Clin Periodontol. 1970 Jan;41(1):41-3.

13. Quigley G, Hein J. Comparative cleansing efficiency of manual and power brushing. J Clin Periodontol. 1962 Jul;19:749-53.

14. Macpherson LM, Stephen KW, Joiner A, Schäfer F, Huntington E. Comparison of a conventional and modified tooth stain index. J Clin Periodontol. 2000 Nov;27(11):854-9

15. Lobene RR, Soparkar PM, Newman MB. Use of Dental Floss effect on plaque and gingivitis. Clin Prev Dent. 1982 Jan-Feb;4(1):5-8.
16. Solis C, Santos A, Nart J, Violant D. $0.2 \%$ chlorhexidine mouthwash with na antidiscoloration system versus $0.2 \%$ chlorhexidine mouthwash: a prospective clinical comparative study. J. Clin Periodontol. 2011 Jan;82(1):80-5.

17. Rathe F, Auschill TM, Sculean A, Gaudszuhn Ch. and Arweiler NB The plaque and gingivitis reducing effecr of a chlorhexidine and aluminium lactate containing dentifrice ( Lacaulu aktiv) over a period of 6 months. J Clin Periodontal 2007 Aug; 34(8):646-51

18. Hoffmann T, Bruhn G, Richter S, Netuschil L, Brecx M. Clinical controlled study on plaque and gingivitis reduction under longterm use of low-dose chlorhexidine solutions in a population exhibiting good oral hygiene. Clin Oral Invest. 2001;5(2):89-95.

19. Oltramari-Navarro PV, Titarelli JM, Marsicano JA, Henriques JF, Janson G, Lauris JR, Buzalaf MA. Effectiveness of $0.50 \%$ and $0.75 \%$ chlorhexidine dentifrices in orthodontic patients: a double-blind and randomized controlled trial. Am J Orthod Dentofacial Orthop. 2009 Nov;136(5):651-6.

20. Sheen S, Banfield N, Addy M. The propensity of individual saliva to cause extrinsic staining in vitro a developmental method. Journal of dentistry. 2001 Feb;29(2)99-102.

\section{Emanuel da Silva Rovai \\ (Corresponding address)}

Instituto de Ciência e Tecnologia

Curso de Odontologia - Depto de Dentística

Av. Francisco José Longo, 777, 12201-000 - São José dos

Campos - SP, Brazil

Date submitted: 2013 Apr 17

Accept Submission: 2013 Jun 03 